\section{Higher numbers} than previously predicted could be incubating vCJD

More people in the United Kingdom than previously thought could be incubating the variant Creutzfeldt-Jakob disease (vCJD), suggests new research.

An analysis of nearly 13000 anonymised appendix and tonsil samples has found that prion proteins associated with vCJD had accumulated in three of them.

However, only one of the samples showed a pattern of prion accumulation that resembled that seen in tissue of known vCID cases. The other two had different patterns of accumulation and their significance is uncertain, although they cannot be dismissed as unimportant, say researchers.

Extrapolating these findings to the UK population most at risk of developing vCJD-those aged between 10 and 30 yearsthe researchers estimate that 237 people in every million, or a total of 3808 people-could potentially be carrying markers for the disease (95\% CI, 49-692 per million).

The study was published online as an "early view" paper (ahead of the printed version) on 21 May in the Journal of Pathology (doi: 10.1002/path.1580; www. interscience.wiley.com/ thejournalofpathology)

Zosia Kmietowicz London

\section{British Columbia can sue tobacco industry for healthcare costs}

A Canadian court ruling last week paved the way for the province of British Columbia to sue the tobacco industry for up to \$C10bn (£4.1bn; \$US7.3bn; $€ 6.1 \mathrm{bn})$ in smoking related healthcare costs.

The unanimous ruling from the British Columbia court of appeal follows a six year battle by the province to push through legislation allowing it to try to recover the costs of treating tobacco related illness, estimated at $\$ \mathrm{C} 500 \mathrm{~m}$ a year.

British Columbia first passed a law allowing it to sue tobacco companies for the recovery of healthcare costs in 1998, but after court challenges from the industry the law was held to be too wide because it would have effects outside the province. It was therefore held to be unconstitutional.

But the redrafted Tobacco Damages and Healthcare Costs Recovery Act is constitutionally valid, the three judge appeal court ruled last week. The industry is expected to appeal to the supreme court of Canada. Clare Dyer legal correspondent, BMJ

\section{European and US groups draw up standards for CME}

Representatives of medical education accreditors in the United States and Europe have developed the first global standards for continuing medical education (CME) and are hoping the one page document will improve the quality of medical education, rein in pharmaceutical companies' influence, and, ultimately, foster the free movement of doctors across borders.

"Free movement is a mark of success, a useful objective," said Dr Murray Kopelow, who helped develop the new standards and is chief executive officer of the Accreditation Council for Continuing Medical Education, the United States's main accrediting body for medical education. "Then we can spend energy on teaching and learning, and not on accreditation."

Dr Kopelow and representatives of the American Medical Association, the European Union of Medical Specialists, and groups from the United Kingdom, Bulgaria, Italy, France, and Spain, agreed to the statement this April at a meeting in Rome.

The accreditors have until 15 June to decide whether to formally adopt the standards. The document will not be published until that date.

Anne Harding Maplewood, New Jersey

\section{European guidelines on hypertension more flexible than those in United States}

Janice Hopkins Tanne New York

European experts in hypertension take a flexible approach to defining and treating high blood pressure, but the European and US guidelines are not really that far apart, said Dr Giuseppe Mancia, chairman of the department of medicine at the University of Milan-Bicocca. "The European goal is reduction of long term cardiovascular risk," he said at the American Society of Hypertension meeting in New York last weekend.

Last year the US guidelines said that the risk of cardiovascular disease began at $115 / 75 \mathrm{~mm}$ $\mathrm{Hg}$ and called systolic pressures of 120 to $130 \mathrm{~mm} \mathrm{Hg}$ and diastolic pressures of 80 to $89 \mathrm{~mm}$ $\mathrm{Hg}$ "prehypertension." Thiazidetype diuretics were recommended for most patients, but two or more drugs would usually be needed to control hypertension (BMJ 2003;326:1104).

The European guidelines say optimal blood pressure is below 120/80 mm Hg; normal blood pressure is $120-129 \mathrm{~mm} \mathrm{Hg}$ systolic and 80-84 $\mathrm{mm} \mathrm{Hg}$ diastolic and "high normal" is $130-139 \mathrm{~mm}$ $\mathrm{Hg}$ systolic and 85-89 $\mathrm{mm} \mathrm{Hg}$ diastolic. The guidelines categorise patients' cardiovascular risk depending on the presence of factors such as older age, smoking, dyslipidaemia, and family history of early cardiovascular disease, as well as considering signs of damage to the left ventricle, kidneys, or arterial wall and whether the patient has diabetes.

Dr Mancia said the difference

between the US and European guidelines was that in calling some pressures "prehypertension," the American guidelines tended to result in patients becoming anxious and led to intrusive lifestyle changes, medical visits, and laboratory tests. Dr Mancia suggested that the concept of prehypertension represented a certain way of looking at things, similar to the idea that the whole of life was a "pre-death experience."

Dr David Lackland, professor of medicine at the University of South Carolina in Charleston, described the programme of the society's regional chapter for implementing the US guidelines in the "stroke belt" of North and South Carolina and Georgia, where rates of stroke, heart attack, and end stage renal disease are high.

Dr Daniel Levy of Framingham, Massachusetts, said there were barriers to implementing goals. Although $69 \%$ of hypertensive patients in the United States are aware of their disorder-compared with only $36 \%$ in the United Kingdom-control was still poor.

"The problem is systolic blood pressure in older patients who have older physicians," he said.

The US guidelines are at www.nhlbi nih.gov/guidelines/hypertension The European guidelines, are at www.eshonline.org/documents 2003_hypertension_practice guidelines.pdf

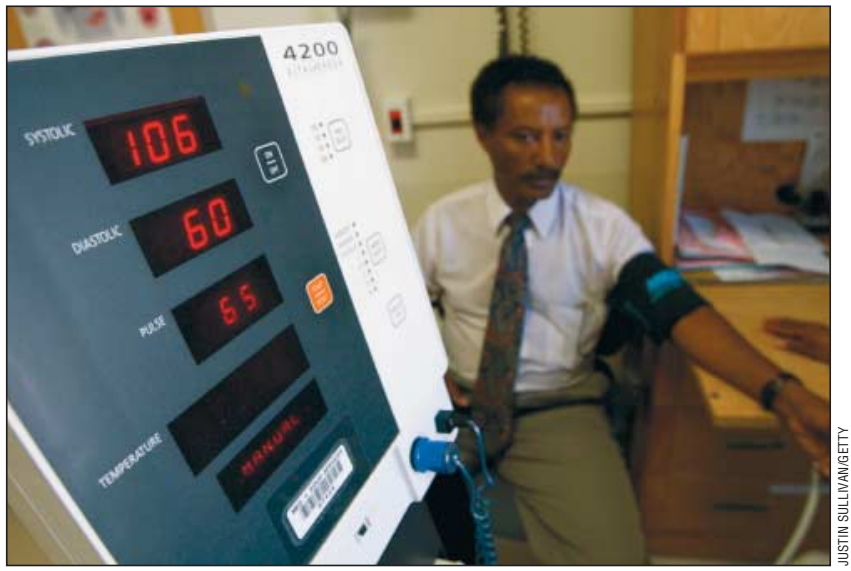

US guidelines suggest that the risk of cardiovascular disease begins at $115 / 75 \mathrm{~mm} \mathrm{Hg}$ 